\title{
Chapter 5 \\ Antimicrobial Resistance and the Private Sector in Southeast Asia
}

\author{
Marco Liverani, Lauren Oliveira Hashiguchi, Mishal Khan, \\ and Richard Coker
}

\begin{abstract}
Southeast Asia is considered a regional hotspot for the emergence and spread of antimicrobial resistance (AMR). A commonality across countries in the region, particularly those with lower incomes such as Cambodia, Myanmar, Lao PDR and Vietnam, is the high utilisation of private healthcare providers, often unregulated, which may play a role in driving AMR. In this chapter we discuss challenges to the control of AMR in Southeast Asia, with a focus on the role of the private sector. After providing an overview of the problem and current policy responses, we consider ethical issues of equity and fairness that may arise from the implementation of established and proposed interventions.
\end{abstract}

Keywords Drug resistance $\cdot$ Ethics $\cdot$ Medicine \& Pubic Health · Private sector · Southeast Asia.

\footnotetext{
M. Liverani ( $ه)$

Department of Global Health and Development, London School of Hygiene and Tropical Medicine, London, UK
}

Faculty of Public Health, Mahidol University, Bangkok, Thailand

School of Tropical Medicine and Global Health, Nagasaki University, Nagasaki, Japan e-mail: Marco.Liverani@1shtm.ac.uk

\author{
L. Oliveira Hashiguchi \\ Department of Global Health and Development, London School of Hygiene \\ and Tropical Medicine, London, UK
}

School of Tropical Medicine and Global Health, Nagasaki University, Nagasaki, Japan e-mail: Lauren.Hashiguchi@1shtm.ac.uk

M. Khan · R. Coker

Department of Global Health and Development, London School of Hygiene and Tropical Medicine, London, UK

Faculty of Public Health, Mahidol University, Bangkok, Thailand

e-mail: Mishal.Khan@1shtm.ac.uk; richard.coker@1shtm.ac.uk 


\subsection{Diversity, Epidemiology and Surveillance Capacity}

Southeast Asia is a loosely defined geographic region, whose configuration is variable and depends on different political, institutional, and cultural perspectives. For the purpose of this chapter, we refer to Southeast Asia as the ten member countries of the Association of Southeast Asian Nations (ASEAN), that is, Brunei, Cambodia, Indonesia, Lao PDR, Malaysia, Myanmar, the Philippines, Singapore, Thailand, and Vietnam. As such, this region includes small, wealthy countries such as Singapore (5.6 million population, US\$ 52,960 per capita) and populous, lower middle-income countries such as Indonesia (261.2 million population, 3570 US per capita) (The World Bank 2017). It is also characterised by socio-cultural differences and vast diversity in ecosystems including farming, natural habitats, and urbanisation. Although gaps remain in our understanding of AMR in Southeast Asia, available evidence indicates that this is an important and growing challenge (Cherau et al. 2017). For example, studies have identified a high prevalence of antimicrobial resistant infections in hospitalized paediatric populations in several regional countries (Al-Taiar et al. 2013; Stoesser et al. 2013; Turner et al. 2016). The Asian Network for Surveillance of Resistant Pathogens (ANSORP) reported rates of pneumococcal resistance to penicillin exceeding 50\% in some contexts (Song et al. 1999) and that resistance had spread across the region. Resistance to enteric pathogens is becoming increasingly prominent (Coker et al. 2017), with studies in Thailand and Cambodia identifying high Campylobacter coli and Campylobacter jejuni rates of resistance to ciprofloxacin among isolate samples from children hospitalized with acute diarrhoea (Bodhidatta et al. 2002; Meng et al. 2011). In terms of respiratory infections, the World Health Organization (WHO) 2016 Global Tuberculosis Report lists Myanmar, Indonesia, Thailand, Philippines, and Vietnam among the 27 countries bearing the highest burden of multidrug resistant tuberculosis in the world (WHO 2015). Drug-resistant malaria is also prevalent across the region, including resistance of the malaria parasite $P$. falciparum to chloroquine, sulfadoxine-pyrimethamine, and most recently, and of considerable concern, artemisinin ( WHO 2017). It is well documented that Western Cambodia, near the border with Thailand, has been an epicentre of antimalarial resistance since the 1950s (Dondorp et al. 2010; Alam et al. 2011; Vinayak et al. 2010). Despite much documentation of resistance throughout the region (Ashley et al. 2014; Imwong et al. 2017), the full epidemiological profile of resistance to antimalarials in Southeast Asia, as with AMR more broadly, is not known.

Fragmented surveillance systems and weak laboratory capacity remain major barriers to acquiring quality surveillance data and information for AMR in the region, especially in LMICs (Lee and Wakabayashi 2013). These barriers were echoed in the findings of the Joint External Evaluation (JEE) (WHO 2016), a WHO-led process to assess country capacity to prevent, detect, and respond to public health threats. In Southeast Asia, JEEs have been conducted in Lao PDR, Vietnam, and Cambodia. Vietnam and Cambodia, the only countries with public JEE reports at present (Joint External Evaluation of the IHR Core Capacities of the Kingdom of 
Table 5.1 Joint external evaluation scoring for AMR Technical Area Indicator, Cambodia and Vietnam (Joint External Evaluation Tool and Process Overview 2016; Joint External Evaluation of the IHR Core Capacities of the Kingdom of Cambodia 2017; Joint External Evaluation of IHR Core Capacities of Viet Nam 2017)

\begin{tabular}{l|l|l|l|l}
\hline & $\begin{array}{l}\text { AMR } \\
\text { detection }\end{array}$ & $\begin{array}{l}\text { Surveillance of } \\
\text { infections caused by } \\
\text { AMR pathogens }\end{array}$ & $\begin{array}{l}\text { Healthcare associated } \\
\text { infection prevention and } \\
\text { control programs }\end{array}$ & $\begin{array}{l}\text { Antimicrobial } \\
\text { stewardship } \\
\text { activities }\end{array}$ \\
\hline Cambodia & 3 & 2 & 2 & 2 \\
\cline { 2 - 5 } & $\begin{array}{l}\text { Developed } \\
\text { capacity }\end{array}$ & Limited capacity & Limited capacity & Limited capacity \\
\hline Vietnam & 2 & 2 & 3 & 2 \\
\cline { 2 - 5 } & $\begin{array}{l}\text { Limited } \\
\text { capacity }\end{array}$ & Limited capacity & Developed capacity & Limited capacity \\
\hline
\end{tabular}

Cambodia 2017; Joint External Evaluation of IHR Core Capacities of Viet Nam 2017), reported limited capacity for surveillance of infections caused by AMR pathogens and advocated improved stewardship to prevent inappropriate use of antimicrobials (Table 5.1) (see also Chap. 23 in this book).

\subsection{Private Health Services and AMR}

The private sector is the dominant health care provider in many countries in the region. For example, about $70 \%$ of Cambodian patients first seek treatment from the private sector and private drug sellers are the preferred healthcare providers for the majority of those who are ill (NIS Cambodia 2014). Across the region, out-ofpocket payment is a common method to finance health care, despite good progress toward universal health coverage in Thailand, Malaysia, Singapore, and Indonesia (Van Minh et al. 2014). Out-of-pocket health expenditure as a percentage of total health expenditure is more than 50\% in Cambodia, Singapore, the Philippines, and Myanmar (Table 5.2) (The World Bank 2017). A study including data from 47 countries indicated that out-of-pocket health expenditure was strongly correlated with AMR in low-income countries, with the authors concluding that high demand for the private sector may be related to higher AMR owing to heightened incentives among private providers to overprescribe and less standardized quality assurance of antimicrobials (Alsan et al. 2015).

Prior to discussing the role of private providers in AMR, it is important to briefly describe the diversity of the private health sector in Southeast Asia and reasons for its popularity. Broadly, private providers include persons operating outside of the government-financed system, alone or in groups, to provide diagnosis, treatment or advice to individuals for health-related concerns. In Southeast Asia, as in other regions, the private sector includes a variety of providers, ranging from large private hospitals, small clinics and pharmacies to road-side informal drug vendors and traditional healers (Khan 2016). The level of training varies greatly. Some private 
Table 5.2 Health sector expenditure indicators in ASEAN (The World Bank 2017)

\begin{tabular}{l|c|l|l|l|l}
\hline & $\begin{array}{l}\text { Population } \\
\text { thousands), } \\
2016\end{array}$ & $\begin{array}{l}\text { GDP } \\
\text { (billions) } \\
2016\end{array}$ & $\begin{array}{l}\text { Health } \\
\text { expenditure as } \\
\text { proportion of } \\
\text { the GDP, 2014 }\end{array}$ & $\begin{array}{l}\text { Public health } \\
\text { expenditure as } \% \\
\text { of total health } \\
\text { expenditure, } \\
2014\end{array}$ & $\begin{array}{l}\text { Out-of-pocket } \\
\text { health expenditure } \\
\text { as \% of total } \\
\text { expenditure on } \\
\text { health, 2014 }\end{array}$ \\
\hline Brunei & 423,196 & 11.4 & $2.7 \%$ & $93.9 \%$ & $6.0 \%$ \\
\hline Cambodia & $15,762,370$ & 20.0 & $5.6 \%$ & $22.0 \%$ & $95.2 \%$ \\
\hline Indonesia & $261,115,456$ & 932.3 & $2.9 \%$ & $37.8 \%$ & $46.9 \%$ \\
\hline Lao PDR & $6,758,353$ & 15.9 & $1.9 \%$ & $50.5 \%$ & $38.9 \%$ \\
\hline Malaysia & $31,187,265$ & 296.4 & $4.1 \%$ & $55.2 \%$ & $35.3 \%$ \\
\hline Myanmar & $52,885,223$ & 67.4 & $2.3 \%$ & $45.9 \%$ & $50.7 \%$ \\
\hline Philippines & $103,320,222$ & 304.9 & $4.7 \%$ & $32.3 \%$ & $53.7 \%$ \\
\hline Singapore & $5,607,283$ & 297.0 & $4.9 \%$ & $41.7 \%$ & $54.8 \%$ \\
\hline Thailand & $68,863,514$ & 406.8 & $4.1 \%$ & $77.8 \%$ & $11.9 \%$ \\
\hline Vietnam & $92,701,100$ & 202.6 & $7.1 \%$ & $54.1 \%$ & $36.8 \%$ \\
\hline
\end{tabular}

practitioners have no training or claim to have qualifications that they do not have, while others have several years of specialist training. In addition to allopathic healthcare providers, there are alternative therapeutic approaches, which include homeopathy and traditional healing. Private providers also vary in terms of the fees charged. Some are highly priced and accessible only to a fraction of the population while others are more accessible and may offer flexible payment arrangements.

Why do patients use the private sector? A recent systematic review comparing the performance of private and public health-care systems in LMICs found that patients' preferences for private providers were related to shorter waiting times, better hospitality, increased time spent with doctors, cleanliness of facilities, longer and flexible opening times, personal attitude, and better availability of staff (Basu et al. 2012). However, quality of care in terms of competence and adherence to guidelines is often low (Morgan et al. 2017).

In terms of AMR specifically, over-prescribing or over-selling of antimicrobial drugs by for-profit healthcare providers appears to be fairly common, although inappropriate prescribing practices have also been reported in public hospitals and health centres (Apisarnthanarak et al. 2008; Om et al. 2017; Yeung et al. 2011). A large study of over 400 healthcare providers including drug shops, private clinics and hospitals in Vietnam found that $79 \%$ would dispense antibiotics for common colds with fever and only $19 \%$ had knowledge of antibiotic prescribing according to national guidelines (Hoa et al. 2009). Drug sellers were more likely to dispense antibiotics inappropriately than other types of healthcare providers in this study. Other studies in the region have shown that, among drugs sold, antimicrobials are very common as they are reported to be the most profit-generating (Gollogly 2002; Chuc and Tomson 1999).

Drug quality is also a problem in the region. There is evidence from Cambodia, particularly on antimalarial drugs (Novotny et al. 2016), and from neighbouring countries such as Vietnam, that unregulated drug shops often sell poor-quality 
medications. According to the WHO, substandard drugs are products whose composition and ingredients do not meet the correct scientific specifications (WHO 2003). This could be due to inappropriate storage at high temperature and humidity or poor quality assurance during the manufacturing process. Both of these conditions are more likely to occur in less-developed countries. Counterfeit drugs are considered a subset of substandard drugs that are deliberately and fraudulently mislabelled with respect to identity and/or source. Antibiotics and antimalarials are at particular risk of targeting by counterfeiters and drug manufacturers that use poor practices owing to large volumes of sales, their relatively low production cost, and the challenges met by regulatory mechanisms and their enforcement. In 2013, a multi-governmental investigation across Cambodia, Indonesia, Lao PDR, Myanmar, Thailand, and Vietnam found that nearly one third of both antimalarials and antibiotics were of poor quality and potentially counterfeited (Weraphong et al. 2013). Similarly, a 2004 cross-sectional survey of pharmacies and drug shops in Myanmar found an "alarming high proportion" of counterfeit artesunate (Dondorp et al. 2004), although a recent survey provides encouraging evidence that the quality of artemisinin-based combination therapies has improved (Yeung et al. 2015).

As noted earlier, this chapter focuses on the use of antimicrobials in human health. But the use in animals is also important, and is a major contributor to AMR globally (Nhung et al. 2015), as further discussed in Chaps. 7 and 18. Subtherapeutic use of antibiotics in livestock for growth promotion or prophylaxis is of particular concern, as the low doses used can lead to the emergence of drug resistance (Van Boeckel et al. 2015). While there are regulations around the use of growth promoters in Europe and America, the use of antibiotics by unregulated veterinarians and drug sellers in Southeast Asia is poorly understood. Multiple studies in the region do, however, indicate a high prevalence of confirmed resistance to ciprofloxacin, and gentamicin, and of particular concern, colistin among $E$. coli isolates in pig and chicken farms (Nhung et al. 2015, 2016; Nguyen et al. 2015, 2016). Colistin is one of the last line of drugs available for treating multidrug resistant Gram-negative pathogens in humans.

\subsection{Policy Challenges in Tackling AMR}

Most governments in Southeast Asia have recognised the dangers of AMR and taken action to control the use of antimicrobials through policy making, legal provisions, and program implementation. Legal frameworks to regulate the pharmaceutical supply chain have been improved in many countries, providing stronger legal bases to counter the problem of substandard medicines and poor management practices (Lamy and Liverani 2015). Operational capacities of drug regulatory authorities have also increased, leading to more effective quality control, closure of unlicensed businesses and a crackdown of the trade in counterfeit medicines, with major enforcement operations being conducted throughout the Mekong region (Interpol 2015). Further, new laws have been introduced to regulate drug sellers, 
particularly for antimalarial medications, although provisions are variable across regional countries. In Thailand, for example, the sale of antimalarial medications in the private sector is banned since 1995, but in other countries regulations are less stringent. In Myanmar, there is no prohibition, while in Lao PDR, the ban applies only to grocery stores, general retailers and itinerant vendors (Akulayi et al. 2017).

Despite increasing commitment, the control of AMR remains a major policy challenge in Southeast Asia, particularly in relation to the sale and use of antibiotics. In Thailand, for example, pharmacists can dispense antibiotics without prescription, leaving more room to profit-motivated sale (Apisarnthanarak et al. 2008; Saengcharoen and Lerkiatbundit 2010). In 2007, the "Antibiotic Smart Use" programme was piloted in community health centres and hospitals to reduce unnecessary prescription of antibiotics for respiratory infections, diarrhoea, and simple wounds. Based on promotional material and performance-based incentives, this programme was subsequently scaled up nationwide and described as a workable model to improve the rational use of antibiotics in Thailand (Akulayi et al. 2017). However, efforts to engage private pharmacies have been less effective (Chalker et al. 2005). In other countries, such as Vietnam and Indonesia, regulations on prescribing and dispensing of antibiotics are more restrictive, but enforcement has been difficult to achieve due to either lack of resources, weak sanctions, or challenges in monitoring compliance in highly diversified markets (Nga et al. 2014; Widayati et al. 2011; Mao et al. 2015). Antimicrobial use is particularly difficult to control in remote rural areas, where access to public health services is more limited, patients tend to self-medicate, and medicines of dubious origin are more likely to be available in road stalls and other informal outlets (Lon et al. 2006; Hadi et al. 2010; Om et al. 2017).

In general, AMR is a complex, multi-dimensional health issue which requires a comprehensive multi-sector policy approach, able to tackle structural drivers and determinants across human and animal health sectors. However, policy development and program implementation have often targeted particular diseases, especially in LMICs where donors have prioritised vertical health programmes. In Cambodia, for example, innovative social marketing schemes have been introduced to improve access to good-quality antimalarials in the private sector and control of pharmaceutical drivers of drug resistance, such as the use of artemisinin monotherapies (Yeung et al. 2011; Yamey et al. 2012). As in other countries, however, no comprehensive policy response to promote the responsible use of medicines has been developed to date. Professional development, supervision, and behaviour change activities are driven by vertical disease programmes as well as the systems for the collection, analysis, and dissemination of surveillance data on antimicrobial resistance. Engagement with the agricultural sector has also been relatively weak in many countries, with gaps in legal provisions and operational capacities to regulate and monitor antibiotic use for animal health prophylaxis and growth promotion (Archawakulathep et al. 2014). Further challenges result from the diversity of the livestock sector in Southeast Asia. While supervision is more feasible in large 
production units, there is less or no control of antibiotic use in smallholders and contracted farmers (Om and McLaws 2016).

In recognition of these challenges and the need for a more comprehensive policy approach, action plans on AMR have been adopted in Cambodia, Indonesia, the Philippines, Thailand, and Vietnam, while the Lao PDR, Malaysia and Singapore are currently developing their national plans (Cheng 2016). In line with WHO global guidelines (WHO 2015), these plans have been informed by One Health approaches and a commitment to strengthening cooperative arrangements across sectors and national authorities. To this end, inter-ministerial and inter-agency committees have been established to guide policy implementation and monitor progress. Since these plans have been adopted only recently, it is too early to assess outcomes and their value in promoting more effective responses to AMR. However, it is expected that the achievement of the stated policy and governance goals will require a significant increase in resource allocation, which may be challenging to achieve in LMICs. Further, as in other contexts, the divisive forces of institutional mandates and professional interests are likely to counteract the imperative of multi-sectoral cooperation, requiring political will at the highest level of policymaking. Finally, as we will see below, achieving a good balance between access to antimicrobials, as well as other vital resources for human and animal health, and curbing inappropriate use and excess is arguably one the most important challenges ahead (Das and Horton 2017), posing key ethical questions about policy choices in the short and the long term.

\subsection{Ethical Issues}

The challenges to controlling the emergence of AMR in Southeast Asia are multisectoral and complex, requiring policies that can address the diverse range of contributing factors, including behaviour and practices, gaps in health service provision and regulations, and macro- and micro-economic drivers in the antimicrobial supply chain and market at the national, regional, and global level. In the process, particular attention should be given to the private health sector and food production systems, as these are arguably the largest channels for the distribution, sale, and use of a wide range of antimicrobials in many regional countries. Yet policy and planning in this area is problematic. In addition to governance challenges noted above, policy options to control AMR in the private sector raise ethical issues of equity and fairness, which have been recognised only recently in research and policy communities (Heyman et al. 2014; Littmann and Viens 2015). While a reduction of antibiotics use is necessary to avert the potentially disastrous impact of future drug-resistant pandemics, a single focus on this policy goal may result in undesirable consequences in the short term, particularly in relation to equitable access to essential goods and services, as we discuss below. 
Access to Health Services Informal providers account for a significant fraction of diagnosis and treatment services in parts of Southeast Asia, raising concerns about the quality of care and their role in driving AMR. Efforts are being made in some countries to ban unlicensed practitioners. However, "village doctors" and other informal providers may be the only accessible source of primary care in some areas, particularly in remote rural communities where public health facilities are hard to reach and other options are not available. In such contexts, regulatory enforcement may be necessary to control potentially harmful practices and key drivers of AMR, but may also reduce access to care where it is needed most. Engagement with the informal sector, including training and supervision programmes, might be a solution to this problem. Yet informal providers have weak legitimacy in relation to the formal health system. The implicit recognition of unqualified providers as legitimate health workers might be challenging if conducted or sanctioned by government agencies and is likely to face strong opposition from established professional categories. On the other hand, informal providers may be reluctant to participate in projects with public health authorities for fear of being exposed (Khan et al. 2015).

Access to Medicines Policy and regulations on prescription and dispensing of antimicrobials raise similar concerns (see also Chap. 24 in this book). Since 1998, the WHO has urged Member States to "prohibit the dispensing of antimicrobials without the prescription of a qualified health care professional" and to strengthen legislation "to prevent the sale of antibiotics on the informal market" (WHO 1998). In many countries, however, the government health system or other authorised suppliers might not be able to reach all population groups or gaps may exist in their ability to meet the demand for antimicrobials. In Cambodia and Lao PDR, for example, health volunteers have been appointed in remote communities to diagnose suspected malaria cases by using rapid diagnostic tests, administer subsidised artemisinin-based combination therapy (ACT), and refer severe patients to the nearest public health facility (Liverani et al. 2017; Alum et al. 2017). These programmes have been successful in improving adherence to malaria policy and treatment where other health services are either lacking or inadequate. However, informal drug outlets and grocery stores remain the only accessible and affordable suppliers of medicines in some areas or for some hard-to-reach groups such as mobile and migrant workers. In addition, stronger quality control and higher standards are likely to increase the cost of medicines, making them less affordable to the poor. While subsidization of particular categories of antimicrobials, such as anti-malarial and antituberculosis treatments, has been implemented with good results (Novotny et al. 2016; Hill and Mao 2007), this approach might not be feasible for mass-market drugs such as antibiotics.

Access to Food As noted earlier, evidence indicates that the use of antibiotics in the livestock sector is an important driver of AMR (Witte 1998). Thus, it is suggested that this practice should be reduced or banned outright. However, it is also known that regulatory restrictions may have significant economic effects on farmers, as the use of antibiotics allows larger numbers of healthy animals to be 
maintained with lower cost to the producer (National Research Council 1999). Further, the effects of restrictions or bans are likely to be unequally distributed across livestock production systems. While large companies and production units may replace antibiotics with other disease prevention practices and veterinary services, smallholders may not be able to do so, bearing higher cost of regulatory change. Finally, more stringent regulations raise concerns of fairness and equity in access to food. Low and sub-therapeutic use of antibiotics contributes to growth promotion and improved feed efficiency, resulting in lower costs of meat and eggs (National Research Council 1999). While the effect of reduced antibiotics use on the price of meat products is difficult to gauge with precision, organic foods are generally more expensive and therefore less affordable to lower income groups (Chander et al. 2011). As Littman (Littmann and Viens 2015) pointed out, "these considerations do not appear to weigh heavily enough to justify the continuation of current practices"; however, we should recognise, "who will be disadvantaged by proposed policy changes, and discuss what kind of subsidy or compensation may be warranted".

\subsection{Conclusion}

In conclusion, AMR is a complex problem that extends far beyond the technical challenge of reducing or improving the use of antimicrobials, as interventions are likely to have externalities on other important issues for human well-being and livelihood. Thus, in Southeast Asia as in other contexts, policy and planning in this area, and modelling and pilot exercises that provide evidence, will need to incorporate a wide range of issues and a calculation of costs and benefits to individuals, enterprises, and across the whole of society. This will likely require us to find a difficult balance between the urgent need to address the rising challenge of AMR while addressing the moral obligations to broad public health benefits and limiting economic hardship. And all of this within complex social and political environments. Simple solutions are likely to induce undesirable, and perhaps unforeseen, consequences.

\section{References}

Alum, A., A. Andrada, J. Archer, E. Auko, K. Bates, P. Bouanchaud, et al. 2017. The malaria testing and treatment landscape in the southern Lao People's Democratic Republic (PDR). Malaria Journal 16 (1): 169.

Akulayi, L., A. Alum, A. Andrada, J. Archer, E. D. Arogundade, E. Auko, et al. 2017. Private sector opportunities and threats to achieving malaria elimination in the Greater Mekong Subregion: Results from malaria outlet surveys in Cambodia, the Lao PDR, Myanmar, and Thailand. Malaria Journal 16: 180. 
Alam, M.T., S. Vinayak, K. Congpuong, C. Wongsrichanalai, W. Satimai, L. Slutsker, et al. 2011. Tracking origins and spread of sulfadoxine-resistant Plasmodium falciparum dhps alleles in Thailand. Antimicrobial Agents and Chemotherapy 55 (1): 155-164.

Alsan, M., L. Schoemaker, K. Eggleston, N. Kammili, P. Kolli, and J. Bhattacharya. 2015. Out-ofpocket health expenditures and antimicrobial resistance in low- and middle-income countries. The Lancet Infectious Diseases 15 (10): 1203-1210.

Al-Taiar A, M.S. Hammoud, L. Cuiqing, J.K.F. Lee, K.-M. Lui, N. Nakwan, et al. 2013. Neonatal infections in China, Malaysia, Hong Kong and Thailand. Archives of Disease in ChildhoodFetal and Neonatal Edition 98 (3): F249-F255.

Anomaly, Jonathan. this volume. Antibiotics and animal agriculture: The need for global collective action. In Ethics and drug resistance: Collective responsibility for Global Public Health, 299-310. Cham: Springer.

Apisarnthanarak, A., J. Tunpornchai, K. Tanawitt, and L.M. Mundy. 2008. Nonjudicious dispensing of antibiotics by drug stores in Pratumthani, Thailand. Infection Control and Hospital Epidemiology 29 (6): 572-575.

Archawakulathep, A., C.T. Thi Kim, D. Meunsene, D. Handijatno, H.A. Hassim, H.R.G. Rovira, et al. 2014. Perspectives on antimicrobial resistance in livestock and livestock products in ASEAN countries. Thai Journal of Veterinary Medicine 44: 5-13.

Ashley, E.A., M. Dhorda, R.M. Fairhurst, C. Amaratunga, P. Lim, S. Suon, et al. 2014. Spread of artemisinin resistance in Plasmodium falciparum malaria. The New England Journal of Medicine 371 (5): 411-423.

Basu, S., J. Andrews, S. Kishore, R. Panjabi, and D. Stuckler. 2012. Comparative performance of private and public healthcare systems in low- and middle-income countries: A systematic review. PLoS Medicine 9 (6): e1001244.

Boden, Lisa and Dominic Mellor. this volume. Epidemiology and ethics of antimicrobial resistance in animals. In Ethics and drug resistance: Collective responsibility for Global Public Health, 109-121. Cham: Springer.

Bodhidatta, L., N. Vithayasai, B. Eimpokalarp, C. Pitarangsi, O. Serichantalergs, and D.W. Isenbarger. 2002. Bacterial enteric pathogens in children with acute dysentery in Thailand: Increasing importance of quinolone-resistant Campylobacter. The Southeast Asian Journal of Tropical Medicine and Public Health 33 (4): 752-757.

Chalker, J., S. Ratanawijitrasin, N.T.K. Chuc, M. Petzold, and G. Tomson. 2005. Effectiveness of a multi-component intervention on dispensing practices at private pharmacies in Vietnam and Thailand - A randomized controlled trial. Social Science and Medicine 60: 131-141.

Chander, M., B. Subrahmanyeswari, R. Mukherjee, and S. Kumar. 2011. Organic livestock production: An emerging opportunity with new challenges for producers in tropical countries. Revue Scientifique et Technique (International Office of Epizootics) 30 (3): 969-983.

Cheng, L. 2016. State of play of antimicrobial resistance research and surveillance in Southeast Asia. Bonn, Germany: SEA-EU-NET II. Available from: https://sea-eu.net/object/document/274/attach/20161201_State_of_Play_on_AMR_Research__Surveillance_-_FINAL. pdf[Accessed May 2020]

Chereau, F., L. Opatowski, M. Tourdjman, and S. Vong. 2017. Risk assessment for antibiotic resistance in South East Asia. BMJ 358: j3393. https://doi.org/10.1136/bmj.j3393

Chuc, N.T., and G. Tomson. 1999. "Doi moi" and private pharmacies: A case study on dispensing and financial issues in Hanoi, Vietnam. European Journal of Clinical Pharmacology 55 (4): 325-332.

Coker, R.J., B.M. Hunter, J.W. Rudge, M. Liverani, and P. Hanvoravongchai. 2017. Emerging infectious diseases in southeast Asia: Regional challenges to control. Lancet 377 (9765): 599-609.

Das, P., and R. Horton. 2017. Antibiotics: Achieving the balance between access and excess. Lancet 387 (10014): 102-104.

Dondorp, A.M., P.N. Newton, M. Mayxay, W. Van Damme, F.M. Smithuis, S. Yeung, et al. 2004. Fake antimalarials in Southeast Asia are a major impediment to malaria control: Multinational 
cross-sectional survey on the prevalence of fake antimalarials. Tropical Medicine \& International Health 9 (12): 1241-1246.

Dondorp, A.M., S. Yeung, L. White, C. Nguon, N.P.J. Day, D. Socheat, et al. 2010. Artemisinin resistance: Current status and scenarios for containment. Nature Reviews in Microbiology 8 (4): 272-280.

Gollogly, L. 2002. The dilemmas of aid: Cambodia 1992-2002. Lancet 360 (9335): 793-798.

Hadi, U., P. van den Broek, E.P. Kolopaking, N. Zairina, W. Gardjito, I.C. Gyssens, et al. 2010. Cross-sectional study of availability and pharmaceutical quality of antibiotics requested with or without prescription (over the counter) in Surabaya, Indonesia. BMC Infectious Diseases 10: 203.

Heyman, G., O. Cars, M.-T. Bejarano, and S. Peterson. 2014. Access, excess, and ethics - Towards a sustainable distribution model for antibiotics. Upsala Journal of Medical Sciences 119 (2): 134-141.

Hill, P.S., and T.E. Mao. 2007. Resistance and renewal: Health sector reform and Cambodia's national tuberculosis programme. Bulletin of the World Health Organization 85: 631-636.

Hoa, N.Q., M. Larson, N.T. Kim Chuc, B. Eriksson, N.V. Trung, and C.L. Stalsby. 2009. Antibiotics and paediatric acute respiratory infections in rural Vietnam: Health-care providers' knowledge, practical competence and reported practice. Tropical Medicine \& International Health 14 (5): 546-555.

Imwong, M., K. Suwannasin, C. Kunasol, K. Sutawong, M. Mayxay, H. Rekol, et al. 2017. The spread of artemisinin-resistant Plasmodium falciparum in the Greater Mekong subregion: A molecular epidemiology observational study. The Lancet Infectious Diseases 17 (5): 491-497.

Interpol. 2015. Falsified and illicit medicines worth USD 7 million seized across Asia in INTERPOL-led operation. Available from: https://www.interpol.int/en/News-and-Events/ News/2015/Falsified-and-illicit-medicines-worth-USD-7-million-seized-across-Asia-inINTERPOL-led-operation [Accessed May 2020].

WHO. 2017a. Joint External Evaluation of IHR Core Capacities of Viet Nam. Geneva: World Health Organization.

WHO. 2017b. Joint External Evaluation of the IHR Core Capacities of the Kingdom of Cambodia. Geneva: World Health Organization.

WHO. 2016. Joint External Evaluation Tool and Process Overview. Geneva: World Health Organization.

Khan, M. 2016. Health markets and antibiotics: Unlikely places you can buy them. Health Policy and Planning Debated Blog, London School of Hygiene and Tropical Medicine. Available from: http://blogs.lshtm.ac.uk/hppdebated/2016/11/29/health-markets-and-antibiotics/\#respond [Accessed May 2020].

Khan, M.S., S. Salve, and J.D.H. Porter. 2015. Engaging for-profit providers in TB control: Lessons learnt from initiatives in South Asia. Health Policy and Planning 30 (10): 1289-1295.

Lamy, M., and M. Liverani. 2015. Tackling substandard and falsified medicines in the Mekong: National responses and regional prospects. Asia \& the Pacific Policy Studies 2 (2): 245-254.

Lee, Y., and M. Wakabayashi. 2013. Key informant interview on antimicrobial resistance (AMR) in some countries in the western pacific region. Global Health 9: 34.

Littmann, J., and A.M. Viens. 2015. The ethical significance of antimicrobial resistance. Public Health Ethics 8 (3): 209-224.

Liverani, M., C. Nguon, R. Sok, D. Kim, P. Nou, S. Nguon, et al. 2017. Improving access to health care amongst vulnerable populations: A qualitative study of village malaria workers in Kampot, Cambodia. BMC Health Services Research 17 (1): 335.

Lon, C.T., R. Tsuyuoka, S. Phanouvong, N. Nivanna, D. Socheat, C. Sokhan, et al. 2006. Counterfeit and substandard antimalarial drugs in Cambodia. Transactions of the Royal Society of Tropical Medicine and Hygiene 100 (11): 1019-1024.

Mao, W., H. Vu, Z. Xie, W. Chen, and S. Tang. 2015. Systematic review on irrational use of medicines in China and Vietnam. PLOS ONE 10: e0117710. 
Meng, C.Y., B.L. Smith, L. Bodhidatta, S.A. Richard, K. Vansith, B. Thy, et al. 2011. Etiology of diarrhea in young children and patterns of antibiotic resistance in Cambodia. The Pediatric Infectious Disease Journal 30 (4): 331-335.

Morgan, R., T. Ensor, and H. Waters. 2017. Performance of private sector health care: Implications for universal health coverage. Lancet 388 (10044): 606-612.

NIS Cambodia. 2014. Cambodia Demographic and Health Survey 2014. Phnom Penh, Cambodia: National Institute of Statistics.

National Research Council. 1999. The use of drugs in food animals: Benefits and risks. Washington, DC: The National Academies Press.

Nga, D.T.T., N.T.K. Chuc, N.P. Hoa, N.Q. Hoa, N.T.T. Nguyen, H.T. Loan, et al. 2014. Antibiotic sales in rural and urban pharmacies in northern Vietnam: an observational study. BMC Pharmacology and Toxicology 15 (1): 6.

Nguyen, V.T., J.J. Carrique-Mas, T.H. Ngo, H.M. Ho, T.T. Ha, J.I. Campbell, et al. 2015. Prevalence and risk factors for carriage of antimicrobial-resistant Escherichia coli on household and small-scale chicken farms in the Mekong Delta of Vietnam. The Journal of Antimicrobial Chemotherapy 70 (7): 2144-2152.

Nguyen, N.T., H.M. Nguyen, C.V. Nguyen, T.V. Nguyen, M.T. Nguyen, H.Q. Thai, et al. 2016. Use of colistin and other critical antimicrobials on pig and chicken farms in Southern Vietnam and its association with resistance in commensal Escherichia coli bacteria. Applied and Environmental Microbiology 82 (13): 3727-3735. http://www.ncbi.nlm.nih.gov/pmc/articles/ PMC4907207/

Nhung, N.T., N.V. Cuong, J. Campbell, N.T. Hoa, J.E. Bryant, V.N.T. Truc, et al. 2015. High levels of antimicrobial resistance among Escherichia coli isolates from livestock farms and synanthropic rats and shrews in the Mekong Delta of Vietnam. Applied and Environmental Microbiology [Internet] 81 (3): 812-820.

Nhung, N.T., N.V. Cuong, G. Thwaites, J. Carrique-Mas. 2016. Antimicrobial usage and antimicrobial resistance in animal production in Southeast Asia: A review. Antibiotics 5 (4). pii: E37.

Novotny, J., A. Singh, L. Dysoley, S. Sovannaroth, and H. Rekol. 2016. Evidence of successful malaria case management policy implementation in Cambodia: Results from national ACTwatch outlet surveys. Malaria Journal 15 (1): 194.

Om, C., and M.-L. McLaws. 2016. Antibiotics: Practice and opinions of Cambodian commercial farmers, animal feed retailers and veterinarians. Antimicrobial Resistance and Infection Control 5: 42.

Om, C., F. Daily, E. Vlieghe, J.C. Mclaughlin, M.-L. Mclaws. 2017. Pervasive antibiotic misuse in the Cambodian community: antibiotic-seeking behaviour with unrestricted access. Antimicrobial Resistance and Infection Control [Internet] 6: 30. Available from: https://doi. org/10.1186/s13756-017-0187-y

Saengcharoen, W., and S. Lerkiatbundit. 2010. Practice and attitudes regarding the management of childhood diarrhoea among pharmacies in Thailand. The International Journal of Pharmacy Practice 18 (6): 323-331.

Song, J.-H., N.Y. Lee, S. Ichiyama, R. Yoshida, Y. Hirakata, W. Fu, et al. 1999. Spread of drugresistant Streptococcus pneumoniae in Asian Countries: Asian Network for Surveillance of Resistant Pathogens (ANSORP) study. Clinical Infectious Diseases 28 (6): 1206-1211.

Stoesser, N., C.E. Moore, J.M. Pocock, K.P. An, K. Emary, M. Carter, et al. 2013. Pediatric bloodstream infections in Cambodia, 2007 to 2011. The Pediatric Infectious Disease Journal 32 (7): e272-e276.

The World Bank. 2017. World Bank Data Bank Available from: http://data.worldbank.org.

Turner, P., S. Pol, S. Soeng, P. Sar, L. Neou, P. Chea, et al. 2016 Aug. High prevalence of antimicrobial-resistant gram-negative colonization in hospitalized Cambodian infants. The Pediatric Infectious Disease Journal 35 (8): 856-861.

Van Boeckel, T.P., C. Brower, M. Gilbert, B.T. Grenfell, S.A. Levin, T.P. Robinson, et al. 2015. Global trends in antimicrobial use in food animals. Proceedings of the National Academy of Sciences of the United States of America 16: 1-6. 
Van Minh, H., N.S. Pocock, N. Chaiyakunapruk, C. Chhorvann, H.A. Duc, P. Hanvoravongchai, et al. 2014. Progress toward universal health coverage in ASEAN. Global Health Action 7. https://doi.org/10.3402/gha.v7.25856.

Vinayak, S., M.T. Alam, T. Mixson-Hayden, A.M. McCollum, R. Sem, N.K. Shah, et al. 2010. Origin and evolution of sulfadoxine resistant Plasmodium falciparum. PLOS Pathogens 6 (3):e 1000830 .

Weraphong, J., S. Pannarunothai, T. Luxananun, N. Junsri, and S. Deesawatsripetch. 2013. Catastrophic health expenditure in an urban city: Seven years after universal coverage policy in Thailand. The Southeast Asian Journal of Tropical Medicine and Public Health 44 (1): $124-136$.

WHO. 2015. Use of high burden countries for TB by WHO in the post-2015 era. Geneva, Switzerland: World Health Organization.

Widayati, A., S. Suryawati, C. de Crespigny, and J.E. Hiller. 2011. Knowledge and beliefs about antibiotics among people in Yogyakarta City Indonesia: A cross sectional population-based survey. BMC Research Notes 4 (1): 491.

Witte, W. 1998. Medical consequences of antibiotic use in agriculture. Science 279: 996-997.

WHO 1998. Emerging and other communicable diseases: Antimicrobial resistance. World Health Assembly (WHA5117). Geneva, Switzerland: World Health Organization.

- 2003. Fact sheet 275: Substandard and counterfeit medicines. Geneva: World Health Organization.

- 2015. Global action plan on antimicrobial resistance. WHO Press, 1-28. Geneva, Switzerland: World Health Organization. Available from: http://www.who.int/drugresistance/ global_action_plan/en/ [Accessed May 2020].

- 2017. Global database on antimalarial drug efficacy and resistance. Geneva, Switzerland: World Health Organization.

Yamey, G., D. Montagu, and M. Schäferhoff. 2012. Piloting the affordable medicines facilitymalaria: What will success look like? Bulletin of the World Health Organization 90 (6): 452-460.

Yeung, S., E. Patouillard, H. Allen, and D. Socheat. 2011. Socially-marketed rapid diagnostic tests and ACT in the private sector: Ten years of experience in Cambodia. Malaria Journal 10 (1): 243.

Yeung, S., H.L.S. Lawford, P. Tabernero, C. Nguon, A. van Wyk, N. Malik, et al. 2015. Quality of antimalarials at the epicenter of antimalarial drug resistance: Results from an overt and mystery client survey in Cambodia. The American Journal of Tropical Medicine and Hygiene 92 (Suppl 6): 39-50.

Open Access This chapter is licensed under the terms of the Creative Commons Attribution 4.0 International License (http://creativecommons.org/licenses/by/4.0/), which permits use, sharing, adaptation, distribution and reproduction in any medium or format, as long as you give appropriate credit to the original author(s) and the source, provide a link to the Creative Commons licence and indicate if changes were made.

The images or other third party material in this chapter are included in the chapter's Creative Commons licence, unless indicated otherwise in a credit line to the material. If material is not included in the chapter's Creative Commons licence and your intended use is not permitted by statutory regulation or exceeds the permitted use, you will need to obtain permission directly from the copyright holder.

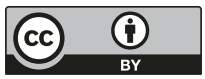

